\title{
Heat Transfer Augmentation Techniques In Various Heat Exchanger By Experimental And Numerical Methods: A Review
}

\author{
Aaruni kumar ${ }^{1}$, Dr. Parag Mishra ${ }^{2}$, Dr. Ajay Singh ${ }^{3}$ \\ ${ }^{1}$ M.E. Scholar, ${ }^{2}$ Associate Professor ${ }^{3}$ Professor and Head \\ ${ }^{1,2,3}$ Mechanical Engineering Department, Radharaman Institute of Technology and Science Bhopal, Madhya \\ Pradesh, India. \\ Iaarunikr1202@gmail.com, ${ }^{2}$ parag.mishra05@gmail.com, ${ }^{3}$ ajaysinghrits@gmail.com
}

\begin{abstract}
Heat exchanger is important appliance in field of thermal, heat mass, fluid flow, in nuclear reactor, steam power plant (in super heater), fertilizers factory, etc. This report presents comparative study of u-tube, spiral \& helical coils for different heat transfer parameters by using SOLIDWORKS and ANSYS FLUENT. The experimental results are compared with CFD calculations results using the CFD package FLUENT 16.2 although experimental setup is fabricated by other group. The objective of this paper is to investigate methods of heat transfer augmentation in various tube type heat exchangers and to find out deviations between experimental and numerical studies. By the studies of the literature, this can be concluded that tubes which can impart greater turbulence also perform better with respect to heat and flow parameter. The future scope of this investigation is to compare modification provided in form of groove and insert and to find out which one is better further to develop a correlation between dimension of modification and heat and flow parameter.
\end{abstract}

Key Words: Heat exchanger, helical coil, U-tube coil, helical coil, spiral coil, Nusselt number, Overall heat transfer coefficient.

\section{INTRODUCTION}

Heat exchanger is a device which is used to transfer heat from one fluid to another fluid by direct or indirect contact. A heat exchanger works as a medium of heat transfer between two fluids i.e. cold and hot fluid. CFD is initials stands for Computational Fluid Dynamics, but as the name tells its scope is not only limited to fluid dynamics. So computational fluid dynamics basically stands for computational transport phenomena, which investigates fluid dynamics, heat transfer, mass transfer or any process which involves exchange of energy and mass. There are many important and challenging applications exist in the nature that we have for CFD these days. So brief discussion on the interesting applications of CFD is provided here, first application which has been the most common one is the aerospace application exterior of an aero plane is considered as an aero file section and there is a flow past an aero file section, which is modeled through CFD.[7]

Automobiles and aircraft applications are very traditional applications of CFD, But there are many applications which are not so traditional, but are very importantly used in modern day applications, like the biomedical applications. Under these applications flow patterns in bronchial tubes, Flow through arteries and human heart (being modeled as a sort of a pump) falls in category of CFD applications. There is an example also where it is not fluid flow, but heat transfer which is being modeled through CFD. Thus from above discussion this can be concluded that now-a-days approaches to experimentation is very sophisticated. And in fact, CFD plays a big role towards good experimentation. Now the question which needs answer is that what are the basic principles that govern the implementation of CFD. They actually are fundamental principles of conservation which govern the basic equations that are commonly used for CFD.

\section{LITERATURE REVIEW}

Changzhao Pan et al. analysed a helical section of fluid flow zone with the rectangular cross-sectional area. Flow is considered oscillating. Helium is as working fluid for the analysis. Also comparison of the results is made with the helical tube of circular section having same cross-sectional area keeping the pitch constant for both the sections. After analysing the results it can be said that friction factor is found smaller and $\mathrm{h}$ is found lager in the section with maximum length to width ratio also at larger frequencies exchanger with rectangular section has performed better than the exchanger with circular section.[1]

Prof. S. S. Pawar et al. investigated on "Comparison of experimental heat transfer parameters for u-tube, spiral \& helical coils of same length with CFD result". This report presents on comparative study of u-tube, spiral \& helical coils for different heat transfer parameters by using solidworks and ansys fluent. the experimental results are compared 
International Journal of Research in Advent Technology, Vol.7, No.3, March 2019

$$
\text { E-ISSN: 2321-9637 }
$$

\section{Available online at www.ijrat.org}

with CFD calculations results using the CFD package fluent 16.2 and experimental setup is fabricated by other group. Mild steel was chosen as the as material for the construction of the u-tube, spiral \& helical coils. The fluid flowing through the coil was taken as water. while the heat transfer characteristics of u-tube, spiral \& helical coils heat exchanger are available in literature, there exist no publish comparison of experimental and CFD analysis of u-tube, spiral \& helical coils heat exchanger. Heat transfer characteristics of u-tube, spiral \& helical coils heat exchanger for various boundary conditions are compared. [2]

Changzhao Pana et al. studied on "CFD study of heat transfer and pressure drop for oscillating flow in helical rectangular channel heat exchanger" this paper presents analysis of oscillating flow inside rectangular section of helical shaped and evaluation is done for heat transfer and pressure drop numerically. The correlations of three models with different ratios of height to width are obtained. By this paper we come to know that the channel with the largest ratio of length to width has a larger heat transfer rate and a lower friction factor. Performance of helical channel is found better at higher frequencies. [3]

Siddhant Singh Yogesh et al. studied on "Heat transfer and pressure drop characteristics of inclined elliptical fin tube heat exchanger of varying ellipticity ratio using CFD code" this paper present analysis of elliptical tubes equipped with fins by ANSYS 15.0, analysis is carried for different heat and friction characteristics. By this paper we come to know that the colburn factor improved in the beginning and reaches the peak, after that it gets lowered with the improvement in tube inclination. Improvement in ellipticity and Reynold's number decreases the Colburn factor. Friction factor differ in direct proportion with tube inclination and ellipticity ratio, whereas it loweres with the improvement in Reynolds's number. The efficiency index parameter for all the models has been calculated. [4]

HaominYuana et al. studied on "Flow-induced vibration analysis of a helical coil steam generator experiment using large eddy simulation" in this paper numerical study of flow-induced vibration in a helical coil is takes place. Tube vibration data (acceleration and frequency) are sampled and compared with the experimental data. By this paper we come to know that pressure loads from the fluid simulation are transferred to the structural simulation but the resulting structural displacements are not fed back to the fluid simulation. [5]

Xinting Wang et al. "Numerical investigation of shell side performance of a double shell side rod baffle heat exchanger". In this paper, a double shell side rod baffle heat exchangeris proposed, and comparisons with singleshell side rod baffle heat exchanger in terms of the heat transfer and pressuredrop in the shell side are presented. A realizable k-epsilon model is adopted to solve the turbulentflow problem, by this paper we come to know that under same mass flow rate, the heat transfer rate $\mathrm{Q}$ and pressure drop of the double shell side rod baffle heat exchanger are higher than those of the singleshell side rod baffle heat exchanger by $34.5-42.7 \%$ and $41.6-40.6 \%$, respectively. [6]

Vijaya Kumar Reddy $\mathrm{K}$ studied tube in tube exchanger. Study is performed for helical exchanger in ANSYS 14.0. By the study of results it can be said that $f$ increases with the flow velocity and value of $h$ has also improved with velocity of flow. Introduction of baffles have improved the performance of the exchanger. [7]

HaominYuana et al. investigated bank of helical coil placed inside the shell. Working fluid is considered air and water with exchanger tube is made to vibrate A Multiphysics tool kit is developed for the study of the flow pattern. Samples are collected for different tube vibrational frequencies. By the findings of study it can be said that higher variation in velocity and pressure drop is found with complex flow in the tube banks. More accuracy is found in tube response is found for velocities smaller than the critical one. [8]

ZhenyaDuana, et al. investigated on "Comprehensive effects of baffle configuration on the performance ofheat exchanger with helical baffles" in this study variation in helix angle is studied on helical baffle with the help of ansys and gambit. Three kinds of helix angles $\left(20^{\circ}, 30^{\circ}, 40^{\circ}\right)$ were chosen. By this paper we come to know that larger helix angle contributes to lower heat transferrate and lower pressure drop; among all simulated models, heat exchanger with 40 helix angle have the highest heat transfer coefficient per unit pressure drop. [9]

Denise A. Haskins et al. investigated and developed the correlation for the fluid on shell side of concentric coiled tube exchanger arranged in helical fashion. The analysis is performed for the pressure loss in the fluid flowing in shell side. Different liquid e.g. water, helium gas and Liquid sodium are used for the analysis. From the studies of the results it can be said that frictional losses are in direct proportion with the mass for lower Re but in inverse proportion with square of the hydro diameter at lower Re exchanger losses are smaller than ten percent. [10]

Zhi-jiang Jin et al. analysed corrugated tube in spiral fashion with six start, and different flow and heat characteristics have analysed. Focus of analysis is kept on the performance of exchanger on varying the depth of corrugation and pitch. Comparison is also done with the simple tube and with the tube of four starts. By the findings of the study it can be said that for the tube with 6-starts $h$ is better than both simple tube and tube with 4-starts. Although value of $\mathrm{f}$ is found in between them. Also drop in pressure and $f$ both are found to be decreasing with the pitch of 
International Journal of Research in Advent Technology, Vol.7, No.3, March 2019

$$
\text { E-ISSN: 2321-9637 }
$$

\section{Available online at www.ijrat.org}

corrugation. Also depth of corrugation has affected the flow adversely by increasing the resistance of fluid in the flow field. [11]

Fabio Bozzoli et al. experimented effects of corrugation on $\mathrm{h}$ in helical pipe. Eight coils with the pitch of $.31 \mathrm{~m}$ is used for the experiment with approximate coil length of $10 \mathrm{~m}$. by the findings of the study it can be said that corrugation in wall has provide additional $\mathrm{h}$ which in turn have improved the local as well as overall value of $h$. at higher dean numbers the effect of corrugation has improved the value of $h$ up to significant amount, [12]

Altac.Z et al. experimented on "Hydrodynamically and thermally developing laminar flow in spiral coil tubes". In this paper they analyzed heat transfer and flow in spiral tube coil. For this experiment they used CFD code fluent which is available in market commercially.

They examined the effects of the spiral tube pitch, curvature ratio, the Prandtl and the Dean number on the friction factor and the heat transfer numerically. By this paper we come to know that heat transfer enhances on increasing Reynolds number along with friction losses. [13]

Hamid Saffari et al. investigated on multiple turn helical coil for the calculation of hydro-entry length. Investigation is performed on single phase working fluid as well as two phase working fluid. Simulation is carried on software CFD. Comparison with the experimental data is also made. After investigating the results it is seen that with the pipe diameter entry length development improves it also increases with reduction in diameter of coil. Although with increase in void fraction the entry length development is found to be decreasing. [14] Suraj R. Gurav analyzed on "Parametric Comparison of Heat Transfer in Helical and Straight Tube-In-Tube Heat Exchanger". This paper performs comparision between helical and straight tube in tube heat exchanger, by this paper we come to know that helical pipes can be used for heat transfer enhancement in heat exchangers. The purpose of this work is to compare tube-in-tube helically coiled heat exchanger with a straight tube heat exchanger. In current work the fluid to fluid heat exchange is taken into consideration. The actual experimentation is carried out on tube-in-tube helical coil heat exchanger and tube-in-tube straight heat exchanger by keeping mass flow rate constant for both the fluids. [15]

\section{METHODOLOGY}

This paper is all about study of different types of heat exchanger and comparing them to find the best possible heat transfer rate and lower cost. This paper mainly focuses on comparing heat transfer parameter for u-tube, spiral and helical coils of same length with
CFD result, also the comparison of heat transfer in helical and straight tube-in-tube heat exchanger is studied and the result is to be compared using CFD. In CFD analysis first geometry in generated according to problem then mesh is created then after solver solves the governing equation for fluid flow then results is plot this is then validated with experimental results. Numerical methodology consist of three phase namely, pre- processing, processing, and post processing.

In this work a modification in the inner tube of straight tube in tube heat exchanger is proposed and analysis of proposed tube is done through CFD software package. The basic steps followed in the present CFD analysis are discussed here which provide general understanding for the various features of a CFD analysis. At first the problem statement of the flow problem is generated by answering to the following questions: What are the geometry included in the problem statement how can it be modelled in design modular? What are the operating parameters and condition? Which type of dimensionality is required by the model? Which type of the flow domain should be used? What type modelling (steady or unsteady) is suitable? Now after defining the problem statement, the body or object for which analysis is performed is modelled. This step generally includes the preparation the geometry with ANSYS design modular or with any other designing software package. Geometry Approximations and simplifications are required sometimes in order to allow the analysis with appropriate efforts. The geometry of flow problem is modelled in such a way that the inputs can be provided easily for the grid generation.

Basic assumptions used during the analysis are as follows:

i. In order to simplify numerical calculations thickness of outer wall is neglected.

ii. Flow is considered as Turbulent flow through tube with insert and tube with groove.

iii. Steady state heat transfer conditions were assumed.

iv. Incompressible flow is assumed.

v. Fluid properties are assumed to be constant with temperature and pressure throughout analysis.

vi. Natural convention and Radiation are neglected.

vii. Heat transfer is considered conjugate between the two fluids.

viii. Properties of copper are assumed to be constant with temperature throughout the analysis. 
International Journal of Research in Advent Technology, Vol.7, No.3, March 2019

$$
\text { E-ISSN: 2321-9637 }
$$

Available online at www.ijrat.org

\section{OBJECTIVES}

1. To increase the turbulence within the fluid.

2. To obtain higher heat area per unit volume.

3. To increase compactness of heat exchanger.

4. To validate CFD result with experimental result.

\section{CONCLUSION}

We observed that the outlet temperature of spiral coil is more than the other two coils i.e. U-tube and helical coils, for all the flow rate this shows that it is more effective than other two. It is also seen that, as the flow rate increases the Nusselt number also increases of all three coils. The overall heat transfer coefficient of spiral coil is more compared to other two coils as we increases the flow rate the overall heat transfer coefficient increases. After comparison of CFD results with Experimental results it is seen that the CFD predictions match reasonably (+ 5\% deviation) well with the experimental results within experimental error limits. Average percentage increase in heat transfer for Spiral coil with respect to U-Tube coil is $28.75 \%$. Average percentage increase in heat transfer for Spiral coil with respect to helical coil is $15.25 \%$. It can be say that one should go with the spiral coil for compact geometry which is more effective than the other two geometries for same length.

\section{REFERENCES}

[1] Changzhao Pan ; Tong Zhang ; Junjie Wanga, ; Yuan Zhou. (2018): "CFD study of heat transfer and pressure drop for oscillating flow in helical rectangular channel heat exchanger" International Journal of Thermal Sciences, 129, pp. 106-114.

[2] S. S. Pawar ; Harshalkolte ; Suchit bhalerao ; Vishal kakad ; Sachinkharat (2018) : "comparison of experimental heat transfer parameters for u-tube, spiral \& helical coils of same length with CFD result'International Journal of Advance Engineering and Research Development. 5, pp. 2462-2469.

[3] Changzhaopana ; Tong zhanga ; Junjiewanga ; Yuan zhou (2018) : "CFD study of heat transfer and pressure drop for oscillating flow in helical rectangular channel heat exchanger" International Journal of Thermal Sciences. 129, pp. 106-114.

[4] Siddhant singhyogesh ; Arun sacoselvaraj ; Dinesh kumarravi ; Thundilkaruppa raj rajagopal (2018) :"heat transfer and pressure drop characteristics of inclined elliptical fin Tube heat exchanger of varying ellipticity ratio using CFD code" international journal of heat and mass transfer . 119, pp. 26-39.

[5] Haominyuana ; Jerome Solberg ; Elia merzaria ; Adam krausa ; Iulian grindeanu (2017) : "flowinduced vibration analysis of a helical coil steam generator experiment Using large eddy simulation". Nuclear Engineering And Design. 322 , pp. 547-562.

[6] Xinting Wang ; Nianben Zheng ; Peng Liu ; Zhichun Liu ; Wei Liu (2017) : "Numerical investigation of shell side performance of a double shell siderod baffle heat exchanger" International Journal of Heat and Mass Transfer. 108 , pp. 20292039.

[7] Vijaya Kumar Reddy K ; Sudheer Prem Kumar B ; Ravi Gugulothu ; Kakaraparthi Anuja ; Viajaya Rao P (2017) : “CFD Analysis of a Helically Coiled Tube in Tube Heat Exchanger”. 4 , pp. 2341-2349.

[8] Haomin Yuan ; Jerome Solberg ; Elia Merzari ; Adam Kraus ; Iulian Grindeanu (2017) : "Flowinduced vibration analysis of a helical coil steam generator experiment using large eddy simulation". Nuclear Engineering and Design. 322 , pp. 547-562.

[9] Zhenyaduana ; Feng shena ; Xing caoa ; Junmeizhangba (2016) : investigated on "comprehensive effects of baffle configuration on the performance ofheat exchanger with helical baffles" Nuclear Engineering And Design . 300, pp. 349-357.

[10] Denise A. Haskins ; Mohamed S. El-Genk ; (2016) : "CFD analyses and correlation of pressure losses on the shell-side of concentric, helically-coiled tubes heat exchangers. Nuclear Engineering and Design. 305 , pp. 531-546.

[11] Zhi-jiang Jin ; Bu-zhan Liu ; Fu-qiang Chen ; Zhi-xin Gao ; Xiao-fei Gao ; Jin-yuan Qian (2016) : "CFD analysis on flow resistance characteristics of six-start spirally corrugated tube". International Journal of Heat and Mass Transfer. 103 , pp. 11981207.

[12] Fabio Bozzoli ; Luca Cattani ; Sara Rainieri (2016) : "Effect of wall corrugation on local convective heat transfer in coiled tubes". International Journal of Heat and Mass Transfer. 101 , pp. 76-90.

[13] Altac.z ; Altun (2014) : "hydrodynamically and thermally developing laminar flow in spiral coil tubes." 7th international conference on applied energy. 74 , pp. 96-107.

[14] Hamid Saffari ; Rouhollah Moosavi ; Nourooz Mohammad Nouri ; Cheng-Xian Lin (2014) : "Prediction of hydrodynamic entrance length for 
Available online at www.ijrat.org

single and two-phase flow in helical coils". Chemical Engineering and Processing. 86, pp. 9-21.

[15] Suraj r. Gurav ; (2013) : "Parametric comparison of heat transfer in helical and straight tube-in-tube heat exchanger." International Journal of Science and Research (IJSR) 4 , pp. 991-994. 